\title{
EFFECT OF RU ADDITION ON CAST NICKEL BASE SUPERALLOY WITH LOW CONTENT OF CR AND HIGH CONTENT OF W
}

\author{
Yunrong Zheng, Xiaoping Wang, Jianxin Dong, and Yafang Han, \\ Institute of Aeronautical Materials, Beijing 100095, CHINA \\ H. Murakami and $H$. Harada \\ National Research Institute for Metals, 1-2-1, Sengen, Tsukuba, JAPAN
}

\begin{abstract}
The effect of $\mathrm{Ru}$ on two kinds of cast nickel-base superalloys in as-cast, heat-treated and oxidation tested specimens has been characterised by optical metallography and scanning electron microscopy. The evaluation of microstructure confirms the distribution of $\mathrm{Ru}$ in various phases, the beneficial role of $\mathrm{Ru}$ in stabilising microstructure, delaying formation of $\mathrm{M}_{6} \mathrm{C}$ and increasing incipient melting temperature of the alloys. The role of Ru on oxidation resistance is different in various kinds of alloy; in Hf-bearing alloys, it has a beneficial effect, but in a $1.5 \% \mathrm{Cr}$ alloy, the effect of $\mathrm{Ru}$ is not obvious.
\end{abstract}

\section{$\underline{\text { Introduction }}$}

An important aim of developing new cast Ni-base superalloys is to increase the operating temperature of these alloys. One of the most effective ways to increase the stress rupture strength at temperatures above $1050^{\circ} \mathrm{C}$ is to decrease the content of $\mathrm{Cr}$ and increase the content of $\mathrm{W}$ in cast Ni-base superalloys. For example, in the third generation of single crystal superalloys, the content of $\mathrm{Cr}$ has been decreased to the level of $2-4 \mathrm{wt} \%$, and the total amount of refractory elements of W, Mo, Ta and Re is as high as $20 w t \%$ [1]. Among these refractory elements, Re is a unique element which can increase both the high temperature stress rupture strength and the oxidation resistance of the alloys. Re was first used in a conventional casting superalloy NASAII [2], and subsequently used in SC superalloys with Re content of 3-6wt\%[1]. In BIAM, in order to develop a low cost Refree casting Ni base superalloy 601 , which has the stress rupture life of $50 \mathrm{~h}$ under $1100^{\circ} \mathrm{C} / 118 \mathrm{MPa}$, the content of W was increased to $16 \mathrm{wt} \%$, and the content of $\mathrm{Cr}$ was decreased to $1.5 \mathrm{wt} \%[3]$. However, the decrease of $\mathrm{Cr}$ content led to a decrease of oxidation resistance of this alloy, which should be compensated by addition of other oxidation resistant elements.

It has been found that $\mathrm{Ru}$ was a potential alloying element to increase the oxidation resistance, and can replace part of the Re due to its relatively lower density and cost compared with $\mathrm{Re}$ [4]. Since Ru belongs to the Pt family, it has high chemical stability and hence high oxidation resistance. Furthermore, $\mathrm{Ru}$ can strengthen both $\gamma^{\prime}$ and $\gamma$ phases effectively due to its large atomic radius. Based on the above-mentioned considerations, this study was performed.

\section{Experimental procedure}

Two kinds of alloys were selected in order to study the role of $\mathrm{Ru}$; their chemical compositions were listed in Table 1 . Alloy 1 is a commercially cast superalloy $\mathrm{K} 19 \mathrm{H}$ containing $\mathrm{Hf}$, alloy 3 is a trial cast superalloy with low $\mathrm{Cr}$, high $\mathrm{W}$ content selected on the basis of the stress rupture properties under the condition of $1100^{\circ} \mathrm{C} / 118 \mathrm{Mpa}$. Alloy 2 and alloy 4 are both $\mathrm{Ru}-$ bearing modified alloys from alloy 1 and alloy 3 respectively. 
Table 1 Chemical compositions of tested alloys, wt.\%

\begin{tabular}{ccccccccccccc}
\hline Alloy & Co & Cr & Mo & W & Nb & $\mathrm{Ru}$ & $\mathrm{Al}$ & $\mathrm{Ti}$ & Hf & $\mathrm{C}$ & $\mathrm{B}$ & $\mathrm{Ni}$ \\
\hline 1 & 11.8 & 6.0 & 1.9 & 10.3 & 2.3 & - & 5.8 & 1.4 & 1.3 & 0.12 & 0.02 & bal. \\
2 & 11.8 & 6.0 & 1.9 & 10.3 & 2.3 & 3.0 & 5.8 & 1.4 & 1.3 & 0.12 & 0.02 & bal. \\
3 & 9.6 & 1.3 & 1.3 & 16.2 & 1.0 & - & 6.0 & 1.1 & - & 0.10 & 0.024 & bal. \\
4 & 9.6 & 1.3 & 1.3 & 16.2 & 1.0 & 3.0 & 6.0 & 1.1 & - & 0.10 & 0.024 & bal. \\
\hline
\end{tabular}

The distribution of $\mathrm{Ru}$, dendrite segregation and phase precipitation were analysed using optical microscopy (OM) and SEM/EDX for all the alloys. The effect of Ru on the oxidation resistance was investigated by static oxidation test at the temperature of $1100^{\circ} \mathrm{C}$, the composition and morphology of the surface oxide scale after oxidation testing were analysed by using the LV method of SEM. The microstructures after long-time exposure at $1100^{\circ} \mathrm{C}$ for 100 hours were observed for all alloys. In order to determine the influence of $\mathrm{Ru}$ on the solid solutioning of $\gamma^{\prime}$ and the incipient melting point of alloys, the directionally solidified alloys 3 and 4 were heat-treated in the temperature range of $1260-1300^{\circ} \mathrm{C}$, and thus a suitable solid solutioning treatment was determined.

\section{Results and discussion}

\section{Composition selection of trial alloys}

The chemical composition of alloy 3 in Table 1 was designed on the basis of the compositions of $\mathrm{K} 19 \mathrm{H}$ alloy $(6 \mathrm{Cr}-10 \mathrm{~W})$, by decreasing $\mathrm{Cr}$ content to $1.5 \mathrm{wt} \%$ and increasing the total content of $\mathrm{W}+\mathrm{Mo}+\mathrm{Nb}+\mathrm{Ta}$ up to $20 \mathrm{wt} \%$. The chemical compositions of these designed conventional cast alloys and their stress rupture lives are given in Table 2. It is shown from Table 2 that the strength level of alloy $A$ is lower than that of alloys B and C. The precipitation of primary $\mu$ and $\alpha(\mathrm{W}, \mathrm{Mo})$ phases was observed in alloy $D$ due to excessive alloying. The alloy $\mathrm{C}$ contains higher $\mathrm{Ta}$ which causes an increment of primary eutectic $\left(\gamma+\gamma^{\prime}\right)$ phases (Fig.1) and leads to difficulty of solid solutioning treatment. Moreover, $\mathrm{Ta}$ is a high cost element; therefore, alloy B is selected as a trial alloy and named as alloy 3 in Table 1 .

\section{Distribution of $\mathrm{Ru}$}

The distributions of $\mathrm{Ru}$ in the precipitated phases, dendrite and interdendrite regions in alloys 2 and 4 are shown in Table 3.

The compositions of $\gamma^{\prime}$ and $\gamma$ in alloy 4 were determined when $\gamma^{\prime}$ and $\gamma$ were coarser after $1100^{\circ} \mathrm{C} / 100 \mathrm{~h}$ long-term exposure, and the compositions of $\mathrm{M}_{6} \mathrm{C}$ carbides were determined from specimens after higher temperature treatment of $1300^{\circ} \mathrm{C}$.

It can be seen from Table 3 that $\mathrm{Ru}$ hardly enters $\mathrm{MC}$ carbides, and the solubility of $\mathrm{Ru}$ in the $\mathrm{M}_{6} \mathrm{C}$ carbides is higher than that in the MC carbides. However, $\mathrm{Ru}$ has a rather higher solubility in the $\gamma^{\prime}$ and $\mathrm{Ni}_{5} \mathrm{Hf}$ phases. The $\mathrm{Ru}$ concentration in the eutectic $\gamma^{\prime}$ phase is higher than in the secondary $\gamma^{\prime}$ phase, and higher in the $\gamma$ matrix compared with the secondary $\gamma^{\prime}$ phase. The partitioning ratio of $\left(\gamma / \gamma^{\prime}\right)$ is near 1:0.7. Ru is uniformly distributed between dendritic and interdendrtic regions.

Table 2 Chemical compositions of trial alloys and stress rupture lives

\begin{tabular}{|c|c|c|c|c|c|c|c|c|c|c|c|c|c|}
\hline \multirow{2}{*}{ Alloy } & \multirow[t]{2}{*}{$\mathrm{Cr}$} & \multirow[t]{2}{*}{ Co } & \multirow{2}{*}{ W } & \multirow{2}{*}{ Mo } & \multirow{2}{*}{$\mathrm{Al}$} & \multirow{2}{*}{$\mathrm{Ti}$} & \multirow[t]{2}{*}{$\mathrm{Nb}$} & \multirow{2}{*}{$\mathrm{Ta}$} & \multirow[t]{2}{*}{$\mathrm{C}$} & \multirow[t]{2}{*}{ B } & \multirow{2}{*}{$\mathrm{Ni}$} & \multicolumn{2}{|c|}{$\begin{array}{c}\text { Stress rupture life (h) } \\
118 \mathrm{MPa}\end{array}$} \\
\hline & & & & & & & & & & & & $1080^{\circ} \mathrm{C}$ & $1100^{\circ} \mathrm{C}$ \\
\hline $\mathrm{A}$ & 3.0 & 9.9 & 14.0 & 1.9 & 5.6 & 1.2 & 2.5 & - & 0.14 & 0.02 & bal & $61.4,80.1$ & \\
\hline B & 1.3 & 9.6 & 16.2 & 2.1 & 6.0 & 1.1 & 1.0 & - & 0.10 & 0.024 & bal & & $51.3,52.4$ \\
\hline $\mathrm{C}$ & 1.5 & 9.8 & 16.2 & 2.0 & 4.9 & 1.1 & 1.1 & 4.4 & 0.10 & 0.034 & bal & & $65.0,52.1$ \\
\hline D & 1.4 & 9.6 & 16.0 & 2.0 & 5.0 & 1.1 & 1.0 & 6.7 & 0.10 & 0.02 & bal & & $40.0,41.4$ \\
\hline
\end{tabular}

Table 3 Distribution of $\mathrm{Ru}$ in as-cast alloys 2 and 4, wt\%

\begin{tabular}{ccccccccc}
\hline Alloy & Eutectic $\gamma^{\prime}$ & $\gamma^{\prime}$ & $\gamma$ & $\mathrm{Ni}_{5} \mathrm{Hf}$ & $\mathrm{MC}$ & $\mathrm{M}_{6} \mathrm{C}$ & dendrite & interdendrite \\
\hline 2 & 2.94 & - & - & 2.13 & 0.23 & - & 2.96 & 3.06 \\
4 & 2.51 & $2.14^{*}$ & $2.97^{*}$ & - & 0.15 & $0.87^{* *}$ & 2.68 & 2.78 \\
\hline
\end{tabular}

* After $1100^{\circ} \mathrm{C} / 100 \mathrm{~h}$ heat exposure

** After $1300^{\circ} \mathrm{C} / 4 \mathrm{~h}$ heat treatment 

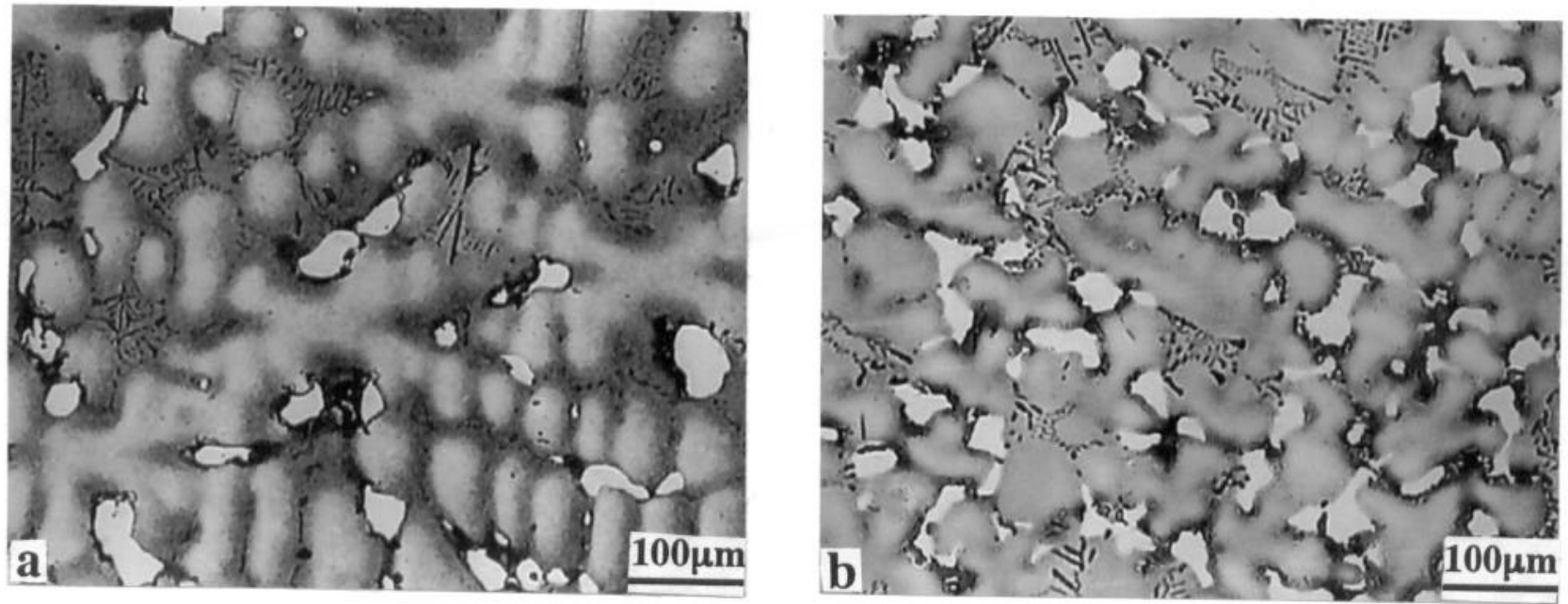

Fig.1 Comparison of eutectic $\left(\gamma+\gamma^{\prime}\right)$ in alloys; (a) alloy B, (b) alloy C.

\section{Effect of Ru on microstructure}

Addition of $3 w t . \%$ Ru in alloys 2 and 4 seems to have no effect on the as-cast microstructures, while it delays the precipitation of $\mathrm{M}_{6} \mathrm{C}$ carbides. After heat treatment at $1100^{\circ} \mathrm{C} / 50 \mathrm{~h}$ for alloy 3 , large amount of coarse-granular or a few short-plate $\mathrm{M}_{6} \mathrm{C}$ carbide particles precipitated along grain boundaries and interdendritic regions (Fig.2). For alloy 4 exposed at $1100^{\circ} \mathrm{C} / 100 \mathrm{~h}$, only at some grain boundary segments were $\mathrm{M}_{6} \mathrm{C}$ particles detected (Fig.3a), and a strong raft tendency of the $\gamma$ ' phase was observed at the dendritic areas (Fig.3b).

Partial solid solution of $\gamma^{\prime}$ phases in dendrites takes place during heat treatment of $1260^{\circ} \mathrm{C} / 4 \mathrm{~h}$ of alloys 3 and 4 . The secondary $\gamma^{\prime}$ phase was completely dissolved except for eutectic $\gamma^{\prime}$ phases in alloy 4 at treatment of $1280^{\circ} \mathrm{C} / 4 \mathrm{~h}$. For alloy 3 , a few secondary $\gamma^{\prime}$ phases existing in the vicinity of the eutectic $\gamma^{\prime}$ were observed, and some necklike $\mathrm{M}_{6} \mathrm{C}$ carbides enveloped by $\gamma^{\prime}$ film existed (Fig.4).

With increasing temperature to $1300^{\circ} \mathrm{C}$ for $4 \mathrm{~h}$, all kinds of $\gamma^{\prime}$ phases were dissolved, but the incipient melting phenomenon apparently occurred in two of the alloys. Compared to alloy 3 , the degree of incipient melting of alloy 4 is lower and it takes place only in some eutectic $\gamma^{\prime}$. For alloy 3 , large parts of the original eutectic $\left(\gamma+\gamma^{\prime}\right)$ region and some columnar grain boundary were melted. The morphology of the incipient melting zone in both alloys is shown in Fig.5. It can be seen from Fig.5 that some block shape or coarse plate $\mathrm{M}_{6} \mathrm{C}$ carbides often appeared in the incipient melting zone and its adjacent zone, especially in alloy 3 . Element $\mathrm{W}$ is the main zomposition of $\mathrm{M}_{6} \mathrm{C}$ carbide and a typical content of metal element in $\mathrm{M}_{6} \mathrm{C}$ carbide of alloy 4 is $72.3 \mathrm{~W}-6.7 \mathrm{Mo}-$ 11.2Ni-3.4Co-1.7Al-0.9Ru-0.7Cr-0.2Ti, This proves that $\mathrm{Ru}$ is not a $\mathrm{M}_{6} \mathrm{C}$ carbide former.

\section{Oxidation resistance of alloys}

Fig.6 shows the experimental results of oxidation tests for the four alloys, Fig.6b is a magnification of Fig.6a. The role of Ru is different in various kinds of alloys. For Hfbearing alloys, $\mathrm{Ru}$ decreases the rate of weight gain slightly, but can drop the rate of weight loss during oxidation testing at $1100^{\circ} \mathrm{C}$. The value of the weight gain decreases from $6.87 \mathrm{~g} / \mathrm{m}^{2}$ to $1.55 \mathrm{~g} / \mathrm{m}^{2}$ in alloy 1 compared with alloy 2 after oxidation test at $1100^{\circ} \mathrm{C}$ for $65 \mathrm{~h}$ due to the decreased flaking of oxide scale.

Observation from SEM has shown that the oxide scale on the surface is porous and contains a crystallographic slope in the Ru-free alloy, as shown in Fig.7a, whereas, the scale of the Ru-bearing alloy is denser and there are nodules existing on some local regions (Fig.7b). On cross sections of the oxidation layer, the continuous scale was observed in alloy 2 (Fig.8a).

For low $\mathrm{Cr}$ alloys, the weight gain was increased during the first 3 hours; even alloy 4 has a larger weight gain. However, spalling of the scale in alloy 4 was later than that of alloy 3. Once spalling of the scale appeared five hours later, the weight loss rate was at the same level in alloys 3 and 4 , about $8.1 \mathrm{~g} / \mathrm{m}^{2} \cdot \mathrm{h}$. The continuous scale did not appeared in alloys 3 and 4, this is apparent from Fig.8b, which shows the serious inter-oxidation in the low $\mathrm{Cr}$ alloy. The compositions of the oxidation layer at alloy 4 after the oxidation test of $1100^{\circ} \mathrm{C} / 50 \mathrm{~h}$ is listed in Table 4 . 

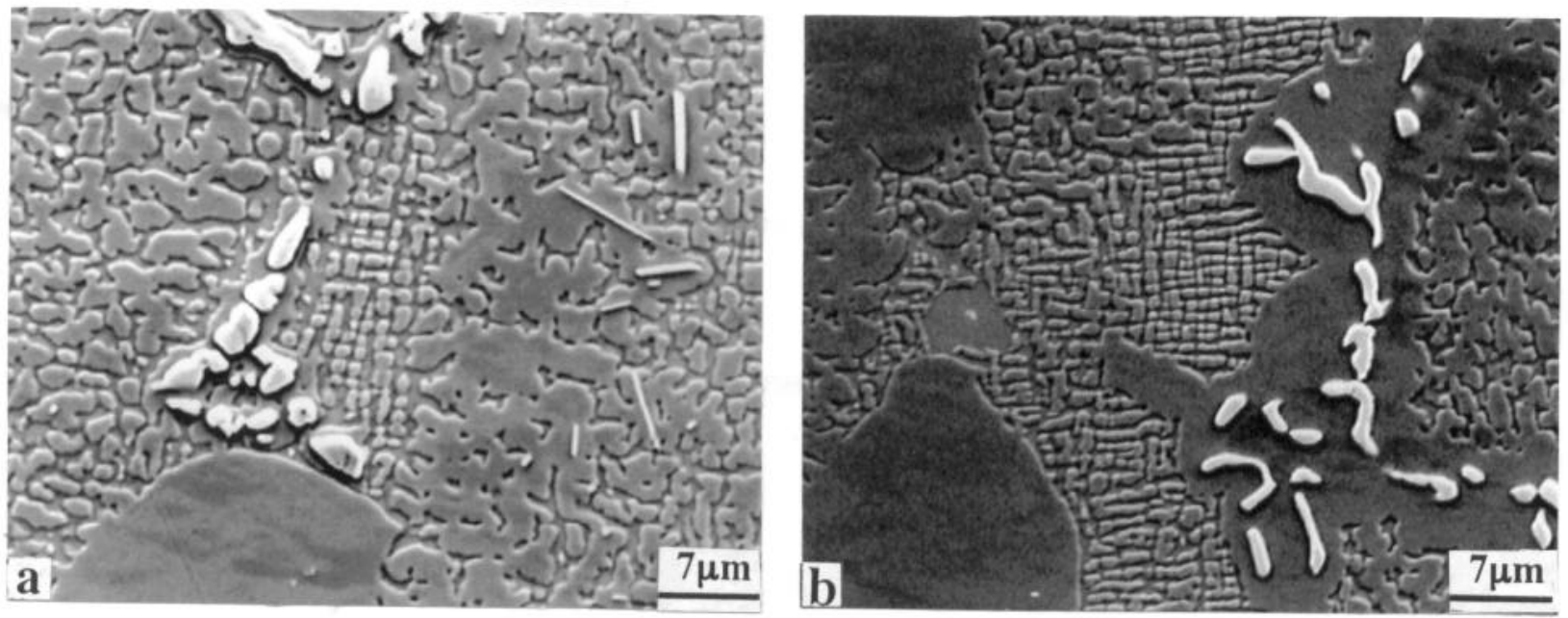

Fig. $2 \mathrm{M}_{6} \mathrm{C}$ carbide precipitated from alloy 3 after $1100^{\circ} \mathrm{C}$ for $50 \mathrm{~h}$;

(a) granular and short-plate $\mathrm{M}_{6} \mathrm{C}$ carbide at interdendrite, (b) $\mathrm{M}_{6} \mathrm{C}$ along grain boundaries.
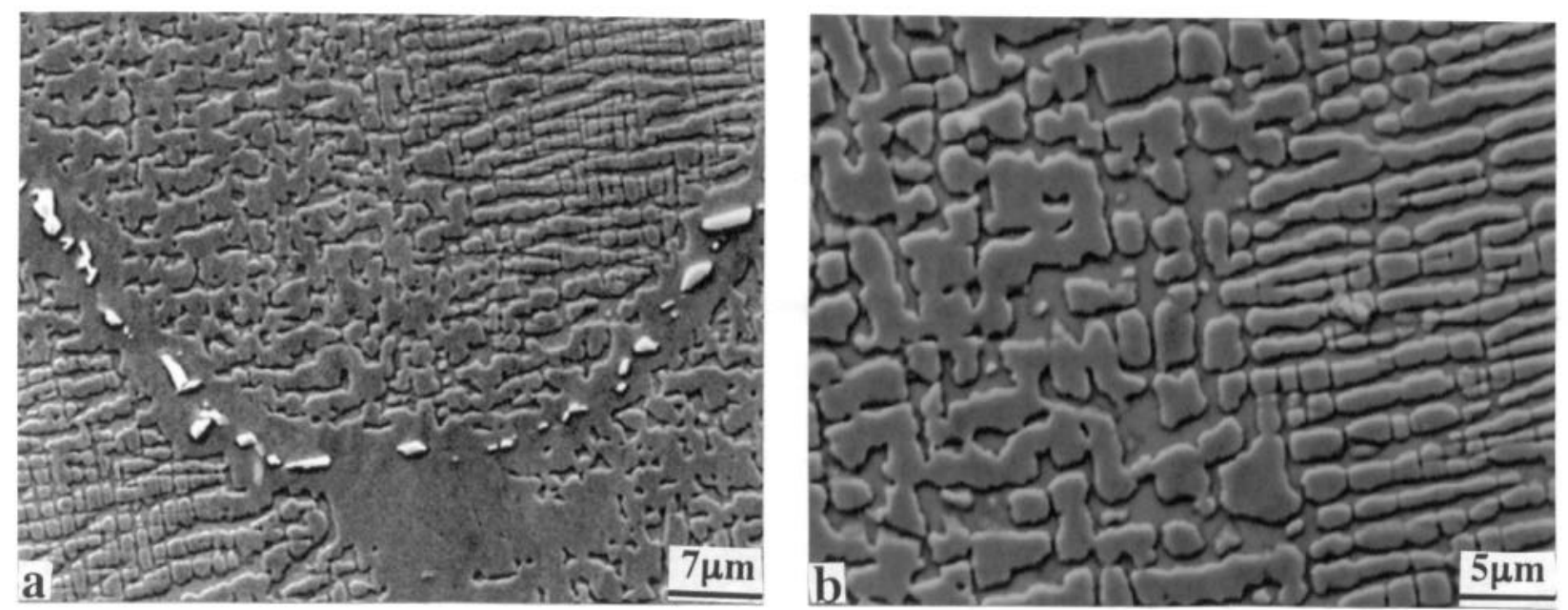

Fig.3 Microstructure of alloy 4 after $1100^{\circ} \mathrm{C}$ for $100 \mathrm{~h}$; (a) $\mathrm{M}_{6} \mathrm{C}$ along grain boundary, (b) rafting $\gamma^{\prime}$ at dendrite.
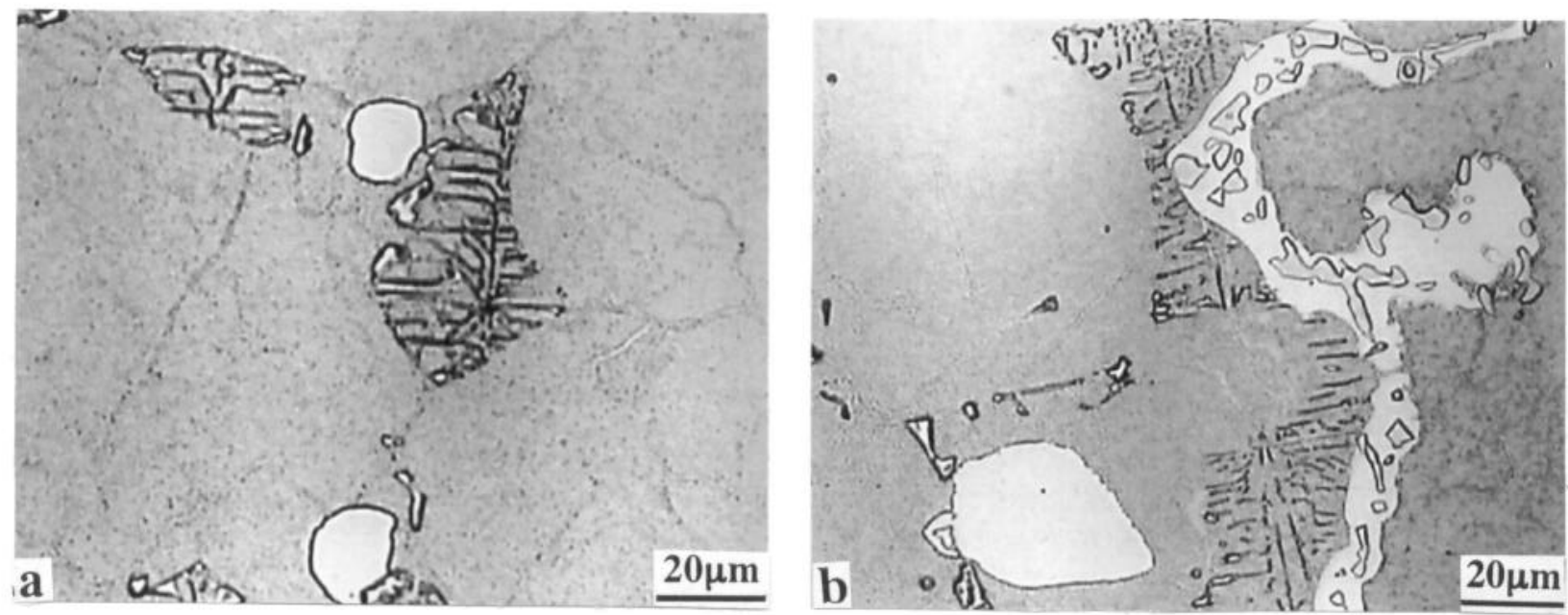

Fig.4 Microstructures after heat treatment at $1280^{\circ} \mathrm{C} / 4 \mathrm{~h}$; (a) alloy 4 (b) alloy 3. 

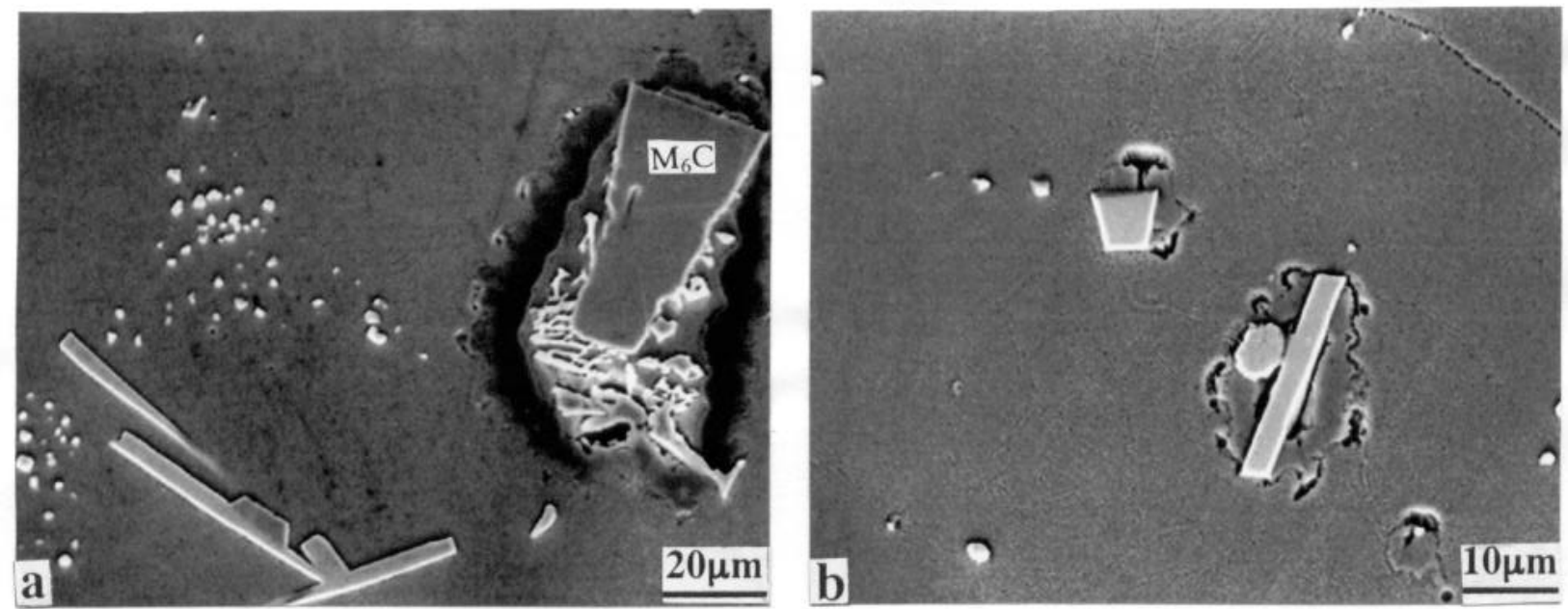

Fig.5 The morphology of incipient melting zones after $1300^{\circ} \mathrm{C} / 4 \mathrm{~h}$ solid solution treatment; (a)alloy 3, (b)alloy 4
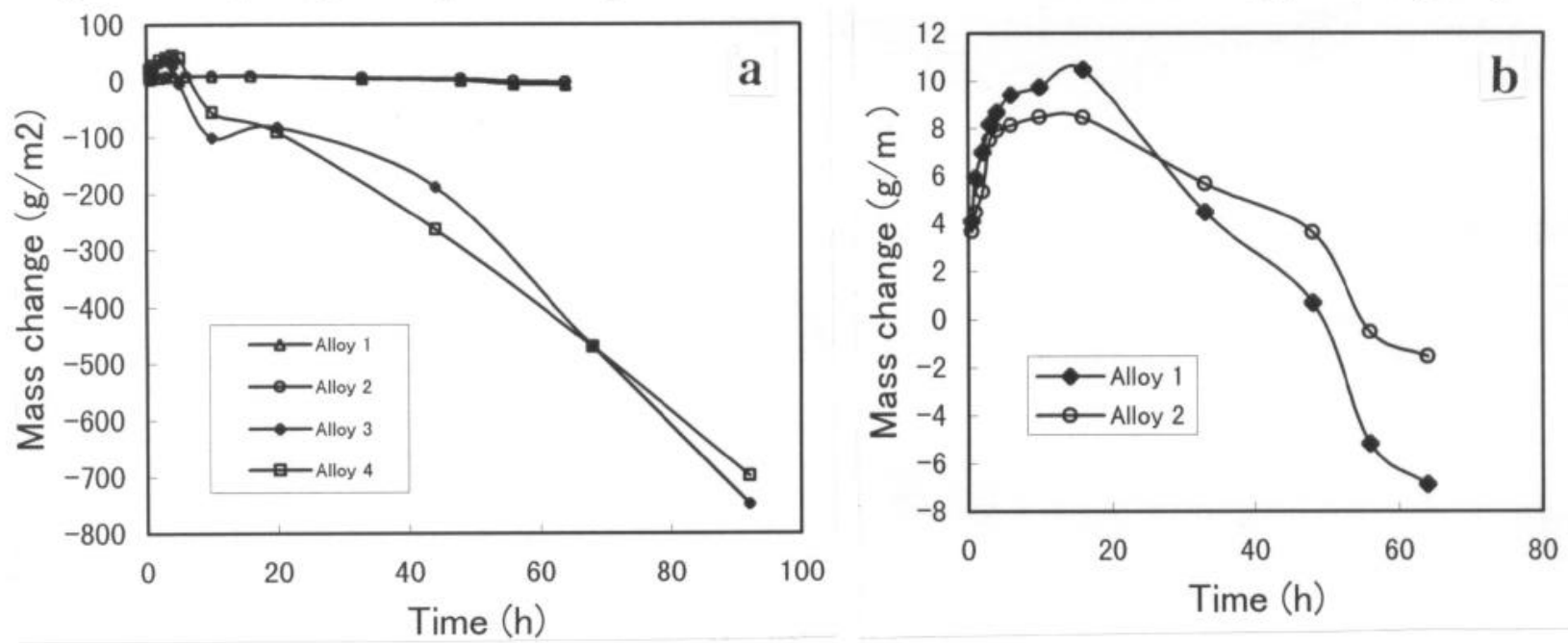

Fig.6 Weight change of alloys during oxidation test at $1100^{\circ} \mathrm{C}$
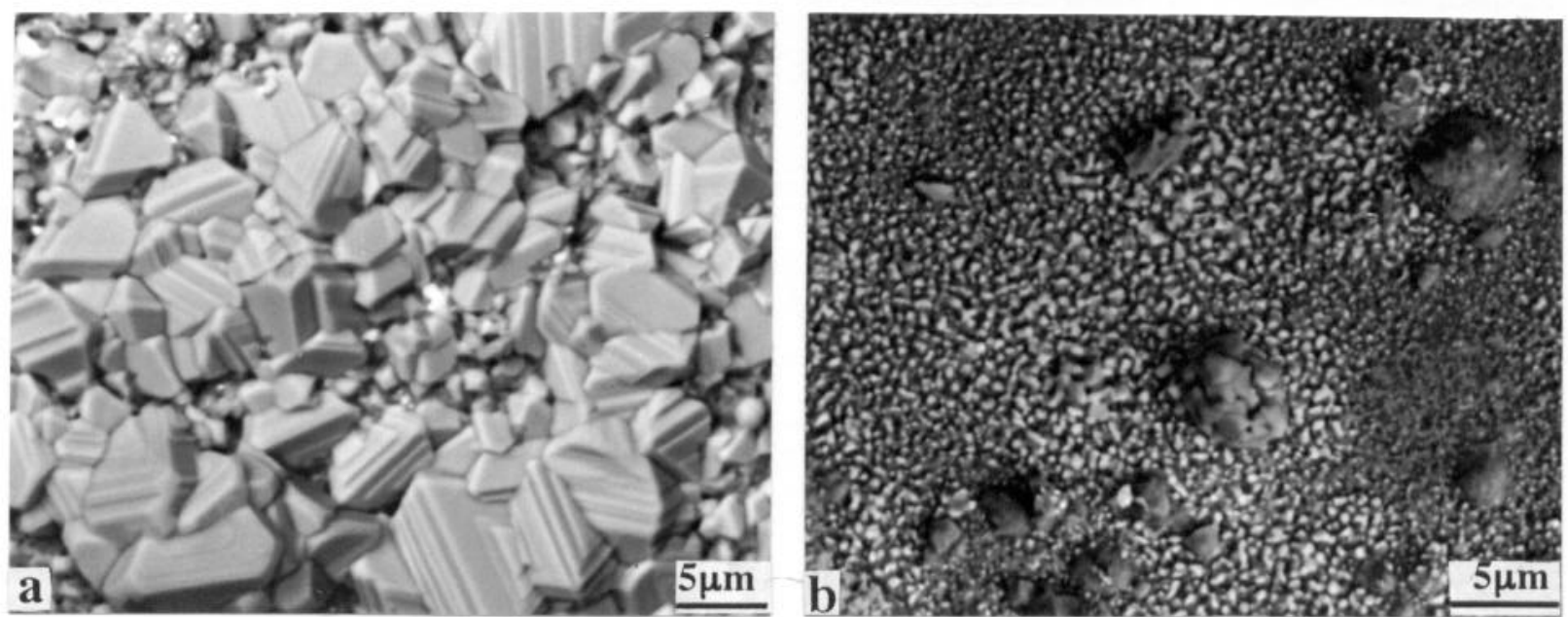

Fig.7 Morphology of scale after oxidation test of $1100^{\circ} \mathrm{C} / 65 \mathrm{~h}$; (a) alloy 1 (b) alloy 2 . 

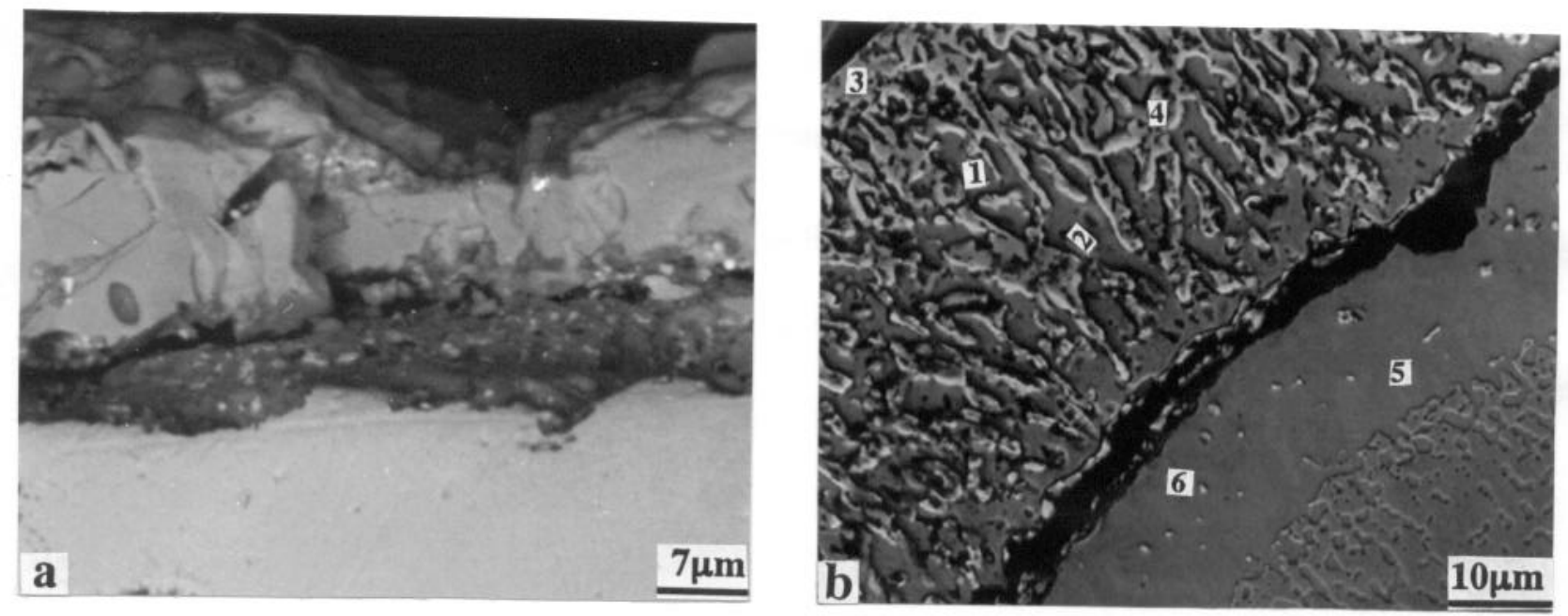

Fig.8 Morphology of oxide layer on alloys after oxidation test at $1100^{\circ} \mathrm{C} / 50 \mathrm{~h}$, (a) alloy 2 (b) alloy 4 .

Table 4 Compositions of oxidation layer on alloy 4 after test of $1100^{\circ} \mathrm{C} / 50 \mathrm{~h}$.

\begin{tabular}{ccccccccccc}
\hline Point & $\mathrm{O}$ & $\mathrm{Al}$ & $\mathrm{Nb}$ & $\mathrm{Mo}$ & $\mathrm{Ru}$ & $\mathrm{Ti}$ & $\mathrm{Cr}$ & $\mathrm{Co}$ & $\mathrm{Ni}$ & $\mathrm{W}$ \\
\hline 1 & 2.26 & 0.21 & 0.36 & 1.35 & 4.26 & 0.22 & 0.35 & 2.69 & 84.67 & 3.63 \\
2 & 2.22 & 0.17 & 0.22 & 0.83 & 3.57 & 0.29 & 0.30 & 1.51 & 87.28 & 3.62 \\
3 & 17.98 & 0.88 & 0.42 & 0.68 & 0.34 & 0.11 & 0.76 & 4.01 & 15.74 & 59.07 \\
4 & 15.40 & 1.01 & 0.36 & 1.04 & 0.42 & 0.36 & 0.61 & 3.57 & 15.87 & 61.35 \\
5 & 2.09 & 2.33 & 0.20 & 1.77 & 1.86 & 0.28 & 1.09 & 9.45 & 58.19 & 22.63 \\
6 & 2.26 & 2.69 & 0.60 & 1.87 & 1.87 & 0.52 & 1.16 & 10.23 & 58.78 & 20.04 \\
\hline
\end{tabular}

The location of the data points is marked in Fig. $8 \mathrm{~b}$. Indeed, large amounts of W-rich oxide particles exist in the Ni matrix, which separates the Ni matrix into small blocks and prevents the formation of a continuous scale.

Structural stability and oxidation resistance are the key points when we develop the low $\mathrm{Cr}$ high $\mathrm{W}$ casting superalloys applied at temperatures over $1100^{\circ} \mathrm{C}$ besides the strength considerations. The excessive alloying by $\mathrm{W}$ usually cause the precipitation of $\alpha$ (W, Mo) and $\mu$ phases [5] and it can be avoided by modifying the composition of alloys. Although Cr-free IC-6 alloy was applied [6], there is still worry about excessive reduction of the oxidation resistance due to the lower $\mathrm{Cr}$ content. Thus, how to affect the oxidation resistance and further improve high temperature strength is the key research topic motivating the substitution of $\mathrm{Ru}$ for $\mathrm{Ni}$.

The experimental results indicate that the substitution $3 w t \% R u$ for $\mathrm{Ni}$ did not cause the precipitation of any new phases. $\mathrm{Ru}$ is a very weak positive segregation element and restricts the formation of $\mathrm{M}_{6} \mathrm{C}$ carbide, which is important for solid solution heat treatment and long time service of high W alloys. For high W free-Ru alloys, large blocky $\mathrm{M}_{6} \mathrm{C}$ carbides (up to $10 \mu \mathrm{m}$ ) were formed after a short time when the temperature is over $1280^{\circ} \mathrm{C}$. The content of $\mathrm{W}$ in $\mathrm{M}_{6} \mathrm{C}$ carbide is up to $70 \%$ reducing the $\mathrm{W}$ content within matrix and $\gamma$ ' phases. Meanwhile, the presence of both coarsening of $\mathrm{M}_{6} \mathrm{C}$ carbides and the formation of $\mathrm{M}_{6} \mathrm{C}$ thin films at the grain boundaries and the interdendrite regions also reduce the high temperature stress rupture properties of high $\mathrm{W}$ alloys. Thus, it is beneficial for the addition of Ru to restrict and delay the formation of $\mathrm{M}_{6} \mathrm{C}$ carbide.

The role of $\mathrm{Ru}$ on the improvement of oxidation resistance is not obvious. It slightly delays spalling of the scale, and does not significantly decrease the weight-loss and weight-gain rate. Especially for the alloy containing $1.5 \mathrm{Cr}$, once the protective scale has not formed, the addition of $\mathrm{Ru}$ did not improve its oxidation resistance, while the addition of $\mathrm{Y}$ can improve the oxidation resistance of Cr-free alloy [7]. It is considered that the contribution to oxidation resistance of $\mathrm{Y}$ is superior to that of $\mathrm{Ru}$. 


\section{Conclusions}

1. $\mathrm{Ru}$ is a weak positive segregation element, which hardly enters into carbide, but has higher solubility in $\gamma^{\prime}$ and $\mathrm{Ni}_{5} \mathrm{HIf}$ phases. The partitioning ratio of $\mathrm{Ru}$ in $\gamma / \gamma^{\prime}$ is about $1: 0.7$.

2. The addition of $\mathrm{Ru}$ in low $\mathrm{Cr}$ high $\mathrm{W}$ alloys can improve the structural stability and delay the $\mathrm{M}_{6} \mathrm{C}$ carbide formation. $\mathrm{Ru}$ slightly increases the incipient melting temperature of alloys.

3. Ru can delay the oxide scale spalling, but does not reduce the oxidation rate for low $\mathrm{Cr}$ high $\mathrm{W}$ alloys. With respect to improvement of oxidation resistance, $\mathrm{Y}$ is superior to $\mathrm{Ru}$.

\section{Reference}

1. W.S. Walston, K.S. O'Hara, E.W. Ross, T.M. Pollock and W.H. Murphy, "RENE N6: Third generation Single Crystal Superalloy", Proc. of the 8th Inter. Symp. on Superalloys, Ed. by R.D. Kissinger et al., TMS, (1996), 27-34.

2. H.E. Collins, "Effect of Thermal Exposure on the Microstructure and Mechanical Properties of Nickel-
Base Superalloys", Metall. Trans., 6(1), 1974, 189204.

3. Zheng Yunrong and Zhang Detang, Colour Mctallographic Invcstigation of Supcralloys and Steels (Beijing, National Defence Press, 1999), 2.

4. Xuan Nguyen-Dinh, "Phase Stable Single Crystal Materials", United Stated Patent Number 4, 935, 072, Jun. 19, 1990.

5. Zheng Yunrong, "Primary $\mu$ Phase in Cast Nickel Base Superalloys", Acta Metallurgical Sinica, 35(12) (1999), 1242-1245.

6. Y.F. Han, Z.P. Xing and M.C. Chaturvedi, 'Development and Engineering Application of a DS Cast $\mathrm{Ni}_{3} \mathrm{Al}$ Alloy IC6", Structural Intermetallics 1997 , Ed. by M.V. Nathal et al., TMS(1997), 713-719.

7. C. Xiao and Y.F. Han, "Effect of Yttrium on the Microstructure and Oxidation Resistance of $\mathrm{Ni}_{3} \mathrm{Al}$ Base Alloy IC6", Journal of Materials Engineering, 1998, no.6: 23-28. 